\title{
KINETICS AND MECHANISM OF OXIDATION OF PYROLLIDINE BY ALKALINE POTASSIUM HEXACYANOFERRATE(III)
}

\author{
S.P. DERANIYAGALA* and R.M. KULASENA ${ }^{1}$ \\ Department of Chemistry University of Sri Jayewardenepura, Nugegoda.
}

(Received : 01 June 1999 ; accepted : 03 December 1999 )

\begin{abstract}
The kinetics of oxidation of pyrollidine by potassium hexacyanoferrate(III) in alkaline medium has been studied. The rate of the reaction was dependent on the first powers of the concentration of the substrate (pyrollidine) and of the oxidant (hexacyanoferrate(III) ion) and inverse first order of the hydrogen ion concentration in the range studied. The final product of the reaction is 1-pyrolline $\mathrm{N}$-oxide commonly referred to as a nitrone. The mechanistic pathway, consistent with kinetic data, including a rapid formation of pyrollidinium anion followed by slow electron transfer to form pyrollidine radical has been proposed.
\end{abstract}

Key words : Kinetics, nitrone, potassium hexacyanoferrate(III), pyrollidine, reaction mechanism.

\section{INTRODUCTION}

Oxidation of organic compounds by metal ions/complexes is well documented ${ }^{1,2}$. In particular, oxidation of amines with one electron oxidants such as hexacyanoferrate (III) ion ( $\mathrm{HCF}$ (III) / $\left.\mathrm{Fe}(\mathrm{CN})_{6}^{3-}\right)$ has been a subject of much interest stimulated by the importance of biological oxidation of amine nitrogen atom ${ }^{3}$. It appears that kinetics of oxidation of cyclic amines by hexacyanoferrate(III) ion has not been investigated so far. In our ongoing effort ${ }^{4}$ (unpublished data, SLAAS,1995) to identify the products and examine rates of oxidation of organic compounds by metal complexes, we report the reaction of a cyclic secondary amine, pyrollidine $\left(\mathrm{Py}, \mathrm{C}_{4} \mathrm{H}_{9} \mathrm{~N}\right)$ with potassium hexacyanoferrate $(\mathrm{III})\left(\mathrm{K}_{3} \mathrm{Fe}(\mathrm{CN})_{6}\right)$ in alkaline medium. The product is a nitrone, a valuable synthetic intermediate and has been utilized for the synthesis of nitrogen containing biologically active compounds such as alkaloids ${ }^{5}$ and $\beta$ lactams. ${ }^{6}$

\section{METHODS AND MATERIALS}

Materials : All chemicals used were of analytical grade and used as received. Pyrollidine ( $>99 \%$ purity), however, was freshly distilled before use.

Theory: The overall reaction can be expressed as

$$
\mathrm{x} F \mathrm{Fe}(\mathrm{CN})_{6}^{3-}+\mathrm{yPy}+\mathrm{z} \mathrm{OH}^{-} \longrightarrow \text { Products }
$$


and the rate law can be expressed as:

$$
\text { Rate }=\mathrm{k}[\mathrm{HCF}(\mathrm{III})]^{\mathrm{a}}[\mathrm{Py}]^{\mathrm{b}}\left[\mathrm{OH}^{-}\right]^{\mathrm{c}}
$$

and more conveniently as : Rate $=\mathrm{k}[\mathrm{HCF}(\mathrm{III})]^{\mathrm{a}}[\mathrm{Py}]^{\mathrm{b}}\left[\mathrm{H}^{+}\right]^{\mathrm{e}}$

Since the decrease in $\mathrm{HCF}$ (III) concentration is monitored, the rate law may be expressed as :

$$
\frac{-d[H C F(I I I)]}{d t}=k[H C F(I I I)]^{a}[\mathrm{Py}]^{b}\left[\mathrm{H}^{+}\right]^{c}
$$

where $\mathrm{k}=$ rate constant, $\mathrm{a}=$ order with respect to $[\mathrm{HCF}(\mathrm{III})], \mathrm{b}=$ order with respect to $[\mathrm{Py}], \mathrm{c}=$ order with respect to $\left[\mathrm{H}^{+}\right]$

By applying pseudo-order conditions i.e. pyrollidine and base are used in excess, then the above equation reduces to:

$$
\frac{-\mathrm{d}[\mathrm{HCF}(\mathrm{III})]}{\mathrm{dt}}=\mathrm{k}_{1}[\mathrm{HCF}(\text { III })]^{\mathrm{a}}
$$$$
\text { where } \mathrm{k}_{1}=\mathrm{k}[\mathrm{Py}]^{\mathrm{b}}\left[\mathrm{H}^{+}\right]^{\mathrm{c}}
$$

If $\mathrm{b}=1$ and low concentrations of HCF(III) obey Beer's law at $420 \mathrm{~nm}$ (figure 1 , $\mathrm{A}=\varepsilon \mathrm{cl})$

Equation 2 can be written as :

$$
\ln \mathrm{A}_{\mathrm{t}}=-\mathrm{k}_{1} \mathrm{t}+\ln \mathrm{A}_{9}
$$

where $A_{t}=$ absorbance of $[H C F(I I I)]$ at time $t, A_{0}=$ initial absorbance of $[H C F(I I I)]$. At constant $\left[\mathrm{H}^{+}\right]$, equation 3 takes the form :

$$
\begin{aligned}
& \ln \mathrm{k}_{1}=\mathrm{b} \ln [\mathrm{Py}]+\ln \mathrm{k}_{2} \\
& \text { where } \mathrm{k}_{2}=\mathrm{k}\left[\mathrm{H}^{+}\right]
\end{aligned}
$$

At constant $[\mathrm{Py}]$, equation 3 takes the form

$$
\begin{aligned}
& \ln \mathrm{k}_{1}=\mathrm{c} \ln \left[\mathrm{H}^{+}\right]+\ln \mathrm{k}_{2} \\
& \text { where } \mathrm{k}_{\mathrm{s}}=\mathrm{k}[\mathrm{Py}]^{\mathrm{b}}
\end{aligned}
$$


Under pseudo-order conditions, but varying the concentration of pyrollidine at constant $\left[\mathrm{H}^{+}\right]$and vice versa, equation 5 and 7 can be utilized respectively to determine the value of $b$ and $c$. Thus the overall rate constant can be calculated using either equation 6 or 8 .

Stoichiometry : The stoichiometry was ascertained by mixing a known amount of pyrollidine with a known excess of potassium hexacyanoferrate(III) in $1 \mathrm{M} \mathrm{NaOH}$ medium at $30^{\circ} \mathrm{C}$ for $3 \mathrm{~h}$. Thereafter the excess hexacyanoferrate(III) was estimated iodometrically using a published procedure? ${ }^{7}$. The results indicated that 1 mole of pyrollidine reacts with 4 moles of hexacyanoferrate(III) ion. The experiment was performed in duplicate to test the reproducibility.
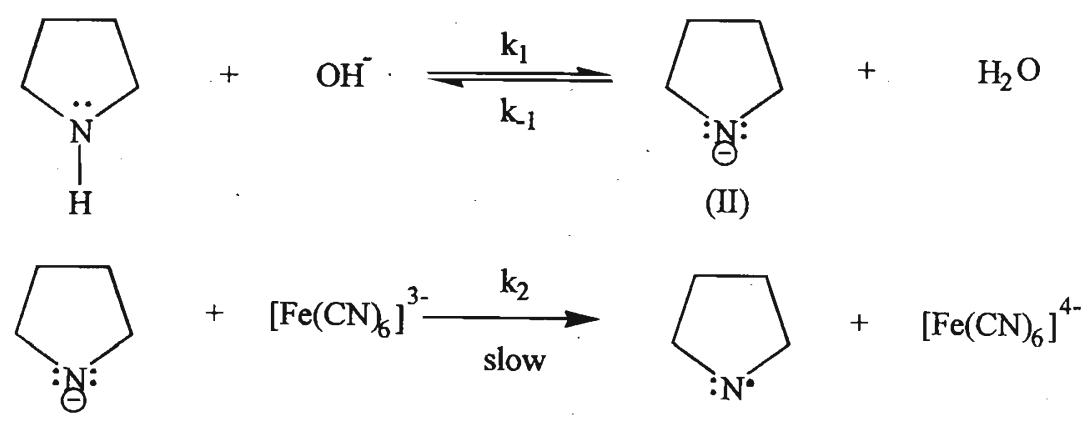

(III)
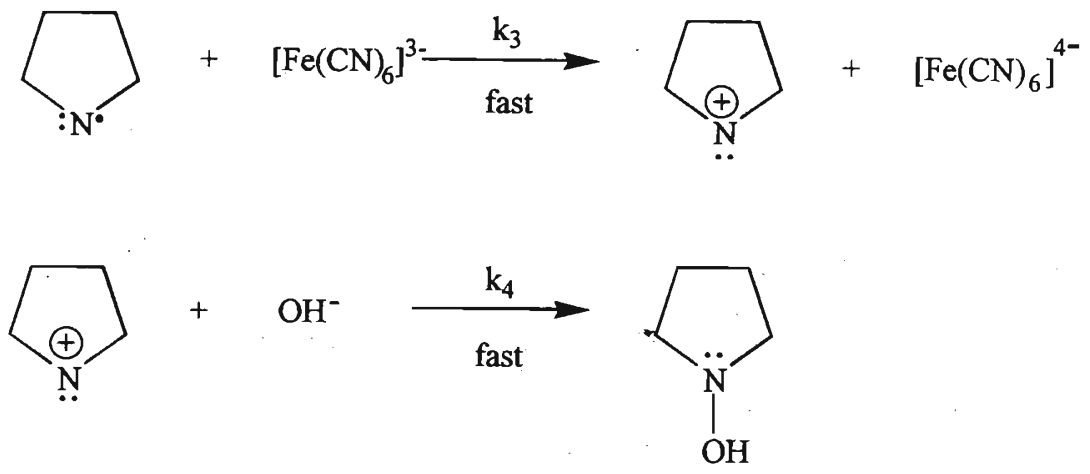

(IV)
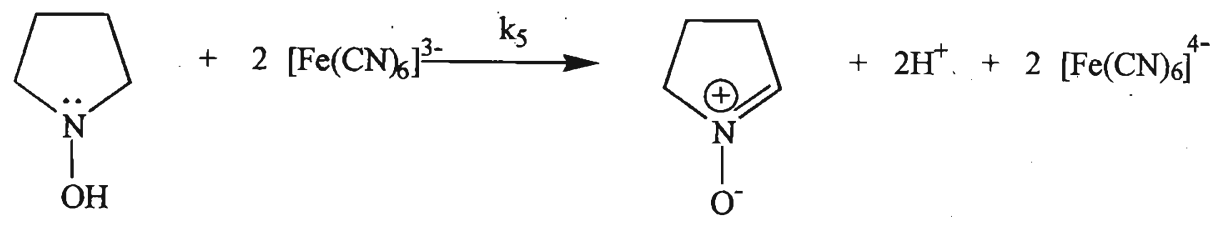

(I) 
Product analysis: Potassium hexacyanoferrate(III) (24g, $0.073 \mathrm{~mol}$ ) was dissolved in $50 \mathrm{~cm}^{\prime \prime}$ of $1 \mathrm{M} \mathrm{NaOH}$ in a $250 \mathrm{~cm}^{\prime}$ stoppered conical flask. To this distilled pyrollidine $\left(1.0 \mathrm{~cm}^{*}, 0.012 \mathrm{~mol}\right)$ was added and shaken well for few minutes. The reaction mixture was allowed to stand for $1 \mathrm{~h}$. with occasional shaking. The aqueous solution was then extracted with methylene chloride $\left(50 \mathrm{~cm}^{3} \mathrm{x} 4\right)$. Column chromatography on alumina (eluent chloroform $/$ methanol $=9: 1$ ) gave the nitrone (1, yield: $42 \%$ scheme 1 ) which was identical in all respect to that obtained by the reaction of pyrollidine with hydrogen peroxide in the presence of selenium dioxide .

Strengths of reagents used in the kinetic study: The concentration of hexacyanoferrate(III) was $2 \times 10^{-3} \mathrm{M}$. The concentration of the pyrollidine was $2.42 \mathrm{M}$. Both solutions were prepared in approximately $1 \mathrm{M}$ sodium hydroxide. These solutions were used to determine the order with respect to hexacyanoferrate(III) and pyrollidine. In the experiment designed to determine the order with respect to $\mathrm{H}^{+}$, the strength of sodium hydroxide was varied from approximately $0.5-0.9 \mathrm{M}$ to prepare hexacyanoferrate(III) and pyrollidine solutions.

Applicability of Beer's law: The applicability of Beer's law for low concentrations of $\mathrm{K}, \mathrm{Fe}(\mathrm{CN})_{6}$, was examined at $420 \mathrm{~nm}$. Figure 1 shows the plot of absorbance versus known concentrations of $\mathrm{K}_{3} \mathrm{Fe}(\mathrm{CN})_{6}$. This is a straight line $(r=0.9997)$ which confirms that Beer's law is obeyed within the concentration range used.

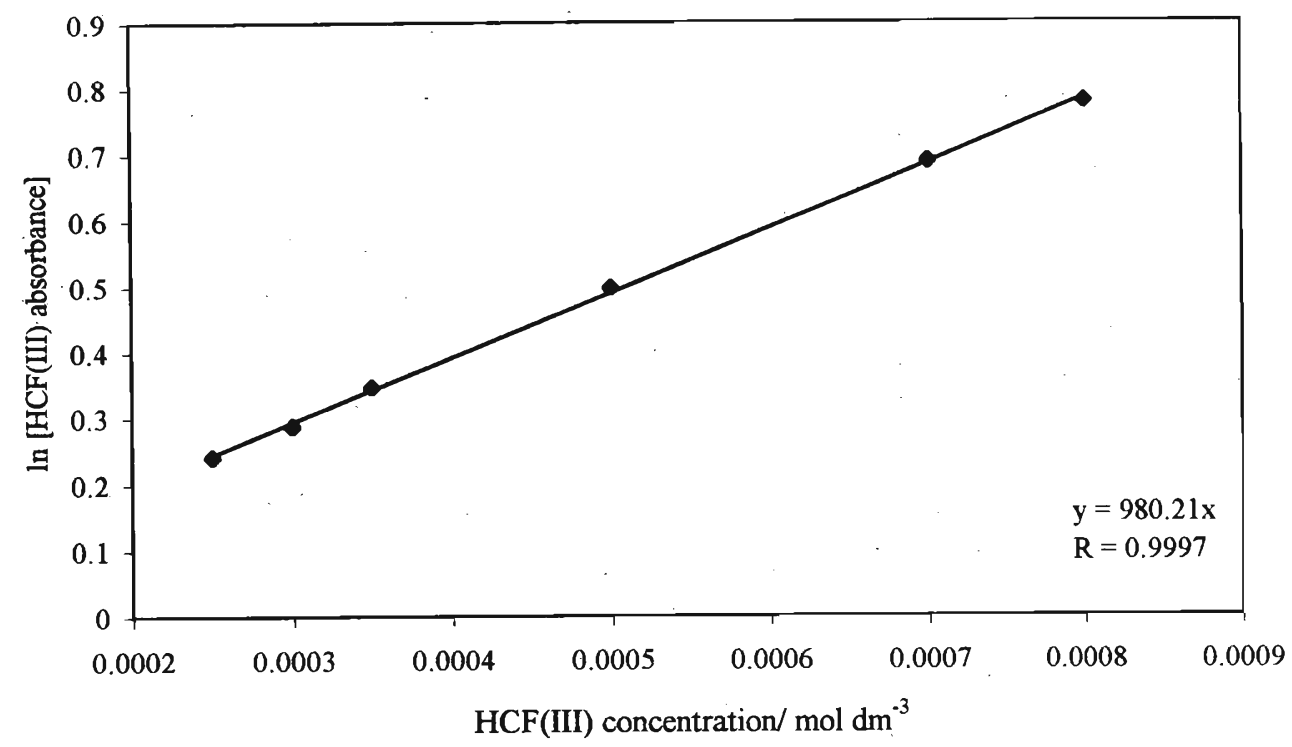

Figure 1: Plot of $\ln \{\mathrm{HCF}$ (III) absorbance / vs concentration of HCF(III) at $420 \mathrm{~nm}$ 
Kinetic Studies: Kinetic studies were carried out under pseudo-order conditions by reacting $\mathrm{K}_{3} \mathrm{Fe}(\mathrm{CN})_{6}$ with excess pyrollidine (Py) under alkaline condition. The progress of the reaction was monitored colorimetrically by measuring the decrease in absorbance of $\mathrm{K}_{3} \mathrm{Fe}(\mathrm{CN})_{6}$ over a period of eleven minutes (at one minute intervals) at $420 \mathrm{~nm}$ at different pyrollidine concentrations at constant $\mathrm{pH}$ and vice versa. In all experiments, the total volume of the reaction mixture was kept at $50.00 \mathrm{~cm}^{3}$.

Determination of $\mathrm{pH}$ : Varying amounts of $2.42 \mathrm{M}$ pyrollidine and $1 \mathrm{M} \mathrm{NaOH}$ were pipetted into a $100 \mathrm{~cm}^{3}$ beaker. The solution was then stirred well for a few seconds by placing the beaker on a magnetic stirrer. The $\mathrm{pH}$ of this solution was then recorded using a Philips PW 9409 digital pH meter. Thereafter $25.0 \mathrm{~cm}^{3}$ of $2 \times 10^{-2} \mathrm{M} \mathrm{K}_{3} \mathrm{Fe}(\mathrm{CN})_{6}$ was added and the reaction mixture stirred for 30 seconds. Timing was started when half the $\mathrm{K}_{3,} \mathrm{Fe}(\mathrm{CN})_{6}$, volume had drained into the beaker containing pyrollidine and base. The stirring was then stopped and $\mathrm{pH}$ recorded at one minute intervals until the reaction mixture became almost colourless. Owing to the high concentration of the base there was no significant change in $\mathrm{pH}$ during the reaction. In the experiment performed to determine the order with respect to $\mathrm{HCF}$ (III) and pyrollidine, $\mathrm{pH}$ varied in the range $12.48-12.52$. Hence an average constant $\mathrm{pH}$ of 12.50 was assumed for all reaction mixtures. In the experiment to determine the order with respect to $\mathrm{H}^{+}$, a similar procedure was followed to record the $\mathrm{pH}$ of each reaction mixture.

\section{RESULTS}

Under the condition $[\mathrm{Py}]>>\mathrm{HCF}$ (III)], the kinetic runs were recorded keeping the concentration of $\mathrm{HCF}(\mathrm{III})$ and $\mathrm{OH}^{-}$at $1 \times 10^{-2} \mathrm{M}$ and $0.032 \mathrm{M}$ respectively and varying the concentration of pyrollidine from 0.72 to $1.11 \mathrm{M}$. Typical volumes used are as follows : HCF(III), $25.0 \mathrm{~cm}^{3}, \mathrm{Py}, 15.0,17.0,19.0,21.0,23.0 \mathrm{~cm}^{3}, \sim 1 \mathrm{M} \mathrm{NaOH}$, $10.0,8.0,6.0,4.0,2.0 \mathrm{~cm}^{3}$. Plots of $\ln$ (absorbance) versus time was found to be straight lines (figure 2, $\mathrm{r}($ mean $)=0.9995)$, co-efficient of variation $=0.08 \%$ ) showing that the reaction is first order ( $\mathrm{a}=1$ ) with respect to $\mathrm{HCF}$ (III) (equation 4). The pseudo first order rate constant $k_{1}$ was calculated from the slopes of the straight lines. From equation 5 , a plot of $\ln \mathrm{k}_{1}$, versus $\ln [\mathrm{Py}]$ was found to be a straight line with a gradient (b) of 0.989 (figure 3 ). This shows first order dependence of rate on pyrollidine.

Kinetic runs were also carried out at different $\left[\mathrm{H}^{+}\right]$at constant pyrollidine (1.0164 M) and $\mathrm{HCF}(\mathrm{III})\left(1 \times 10^{-3} \mathrm{M}\right)$. Typical volumes used were as follows : HCF(III), $25.0 \mathrm{~cm}^{3}$ : Py, $21.0 \mathrm{~cm}^{3}$; $\mathrm{NaOH}, 4.0 \mathrm{~cm}^{3}$ (approximately $0.5 \mathrm{M}, 0.6 \mathrm{M}, 0.7 \mathrm{M}, 0.8 \mathrm{M}$, $0.9 \mathrm{M}) ; \mathrm{pH}$ of reaction mixtures were $12.21,12.27,12.33,12.38$ and 12.42 . Plots of $\ln ($ absorbance) versus time were also linear as shown in figure 4. [ $\mathrm{r}$ (mean) = 0.99986 , co-efficient of variation $=0.009 \%$. A set of $\mathrm{k}_{1}$ values were then calculated from slopes. From equation 7 , a plot of $\ln \mathrm{k}_{1}$ versus $\ln \left[\mathrm{H}^{+}\right]$was also 


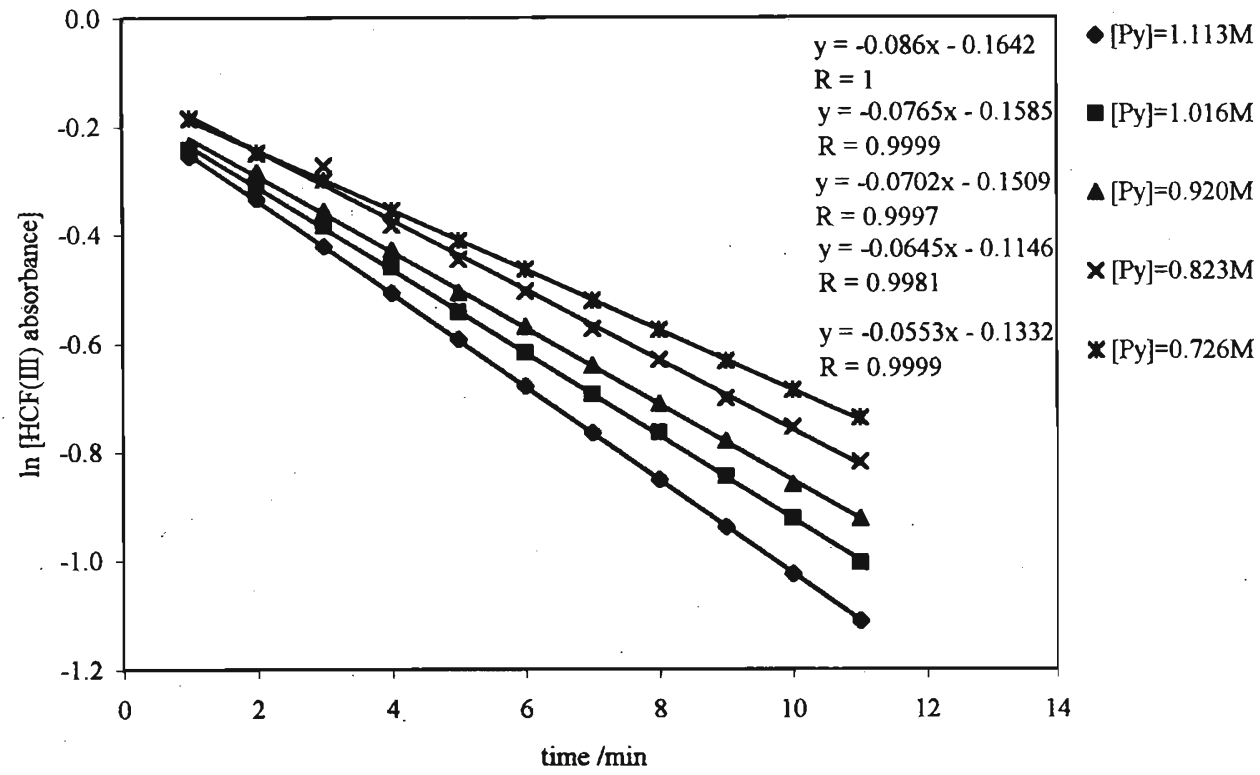

Figure 2: Plot of ln [HCF(III) absorbance] vs time at different [Py]

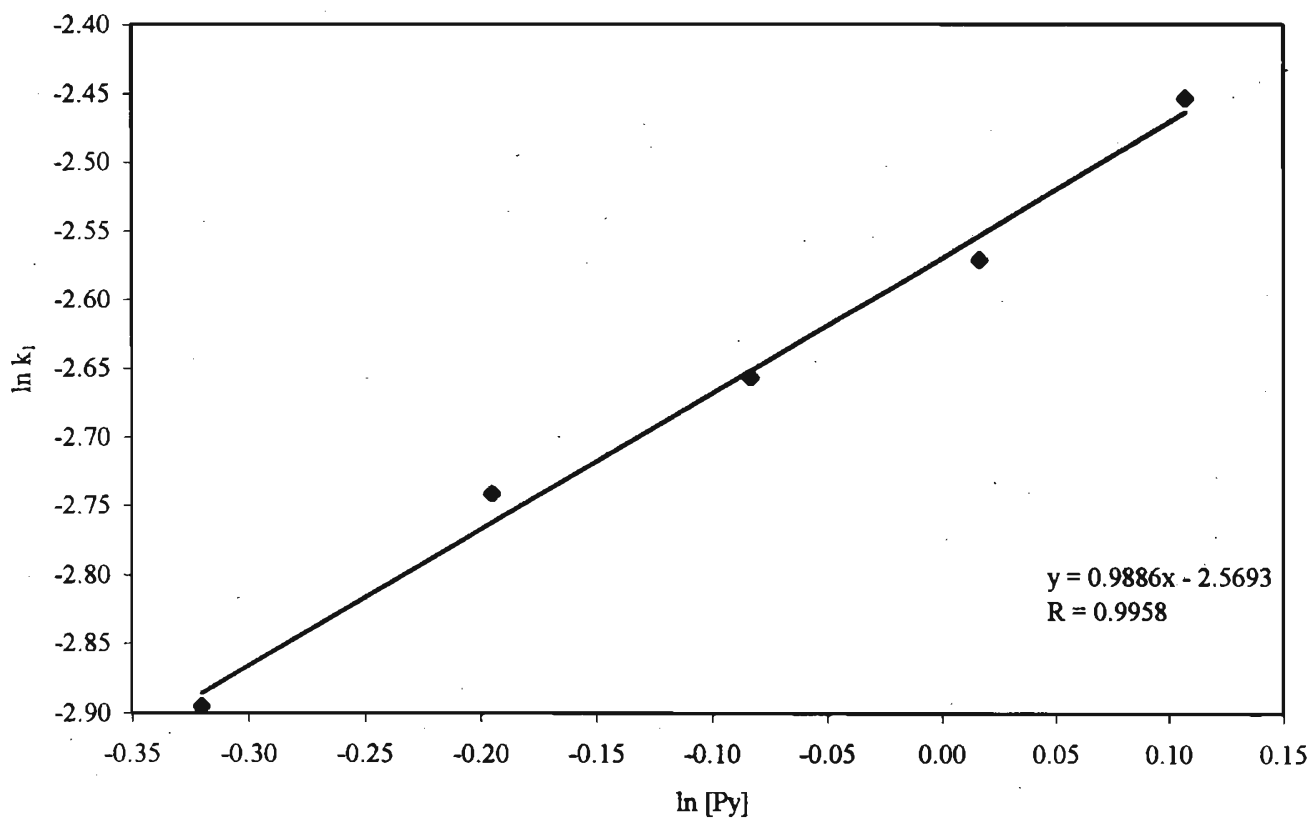

Figure 3 : Plot of $\ln \mathrm{k}$ vs $\ln [\mathrm{Py}]$ at $\mathrm{pH}=12.50$ 


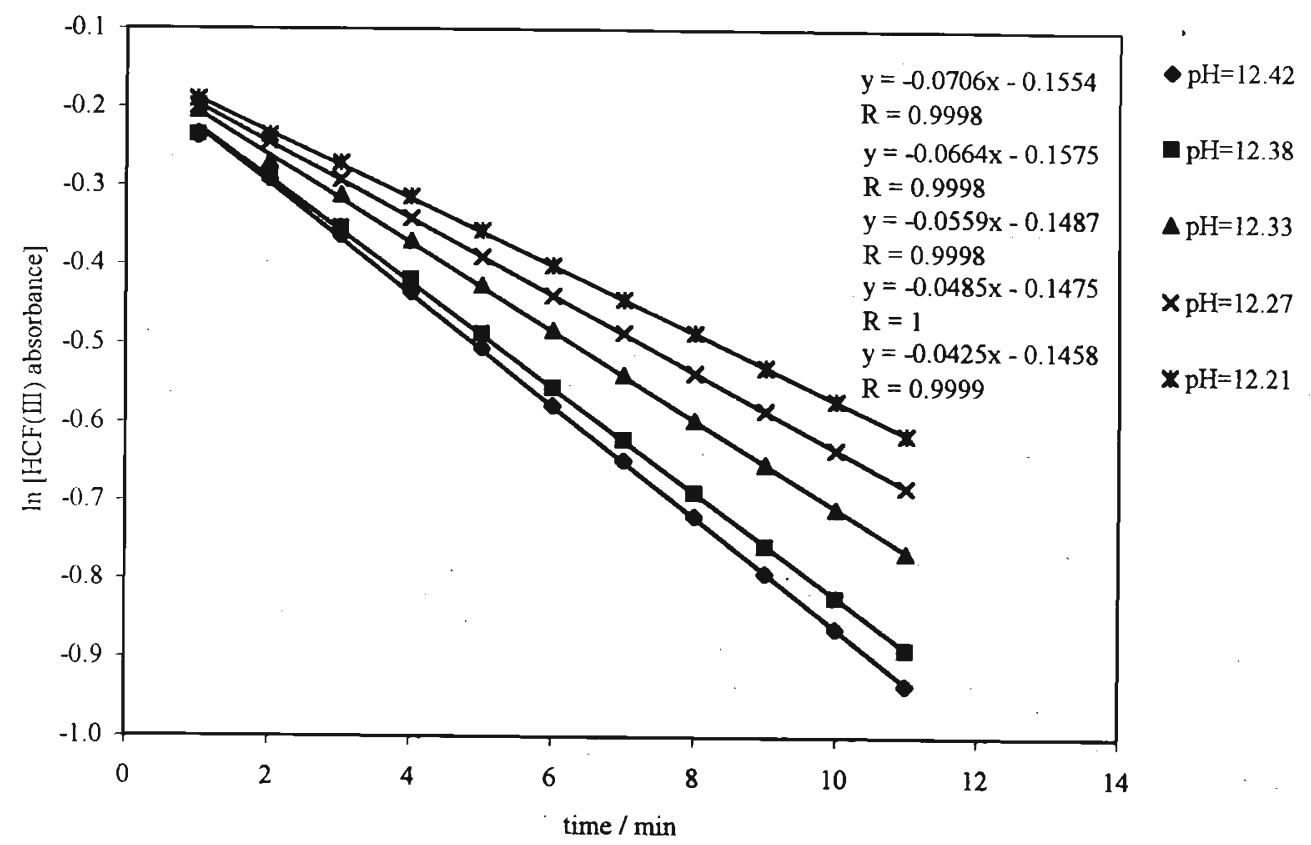

Figure 4: Plot of ln [HCF(III) absorbance] vs time at different pH

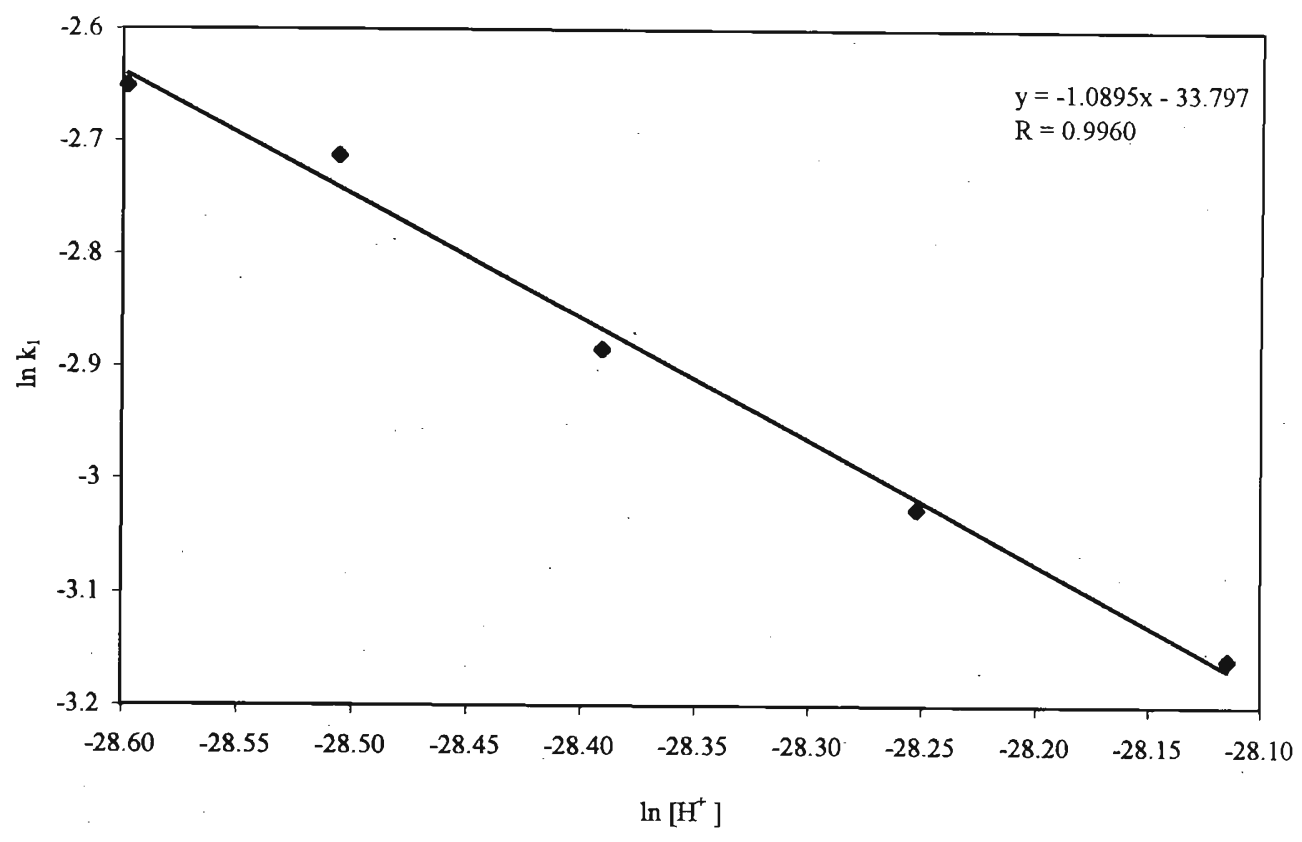

Figure 5: Plot of $\ln k$ vs $\ln \left[\mathrm{H}^{+}\right]$at $[\mathrm{Py}]=1.0164 \mathrm{M}$ 
found to be a straight line $(r=0.9960)$ with a gradient (c) equal to - 1.09 (figure 5). This indicates inverse first order dependence on $\mathrm{H}^{+}$.

The overall rate $\mathrm{k}$ was calculated using equation 6 ,

$$
\mathrm{k}=\frac{\underline{\mathrm{k}}_{2}}{\left[\mathrm{H}^{+}\right]^{c}}
$$

Here $c=-1$ and $k_{2}$ can be calculated from the plot $\ln \mathrm{k}_{1}$ versus $\ln [\mathrm{Py}$ ] (figure 3).

Thus the rate law observed for the oxidation of pyrollidine by $\mathrm{K}_{3} \mathrm{Fe}(\mathrm{CN})_{6}$ in alkaline medium can be written as :

$-\underline{\mathrm{d}}[\mathrm{HCF}(\mathrm{III})]=\mathrm{k}[\mathrm{HCF}(\mathrm{III})][\mathrm{Py}]\left[\mathrm{H}^{+}\right]^{-1}$

$\mathrm{dt}$

where $k$ has been worked out to be $2.42 \times 10^{-14} \mathrm{~s}^{-1}$ at $300 \mathrm{~K}$.

\section{DISCUSSION}

Stoichiometric investigation revealed that four moles of $\mathrm{K}_{3} \mathrm{Fe}(\mathrm{CN})_{6}$, was required to completely oxidize pyrollidine. The product of the reaction was identified as 1-pyrolline $\mathrm{N}$-oxide (referred to as a nitrone) characterized by comparison of spectroscopic data with that of authentic samples". Analysis of kinetic data revealed that the rate law takes the form:

$$
-\underline{\mathrm{d}[\mathrm{HCF}(\mathrm{III})]}=\mathrm{k}[\mathrm{HCF}(\mathrm{III})][\mathrm{Py}]\left[\mathrm{H}^{+}\right]^{-1}
$$

$\mathrm{dt}$

On the basis of these observed experimental facts a stoichiometric mechanism shown in scheme I has been proposed. In this mechanism first step involves the rapid and reversible removal of a proton from the nitrogen atom of pyrollidine to form the stable pyrollidinium anion (II, scheme I) followed by slow electron transfer (rate determining step) to give the pyrollidine radical (III). Further oxidation appears to go via a series of steps culminating in the formation of 1-pyrolline $\mathrm{N}$-oxide. Indirect evidence for the formation of pyrollidine $\mathrm{N}$-hydroxide(IV) was seen from the reaction of pyrollidine with $\mathrm{H}_{2} \mathrm{O}_{2}$ (gives IV) followed by treatment with alkaline $\mathrm{K}_{3} \mathrm{Fe}(\mathrm{CN})_{6}$ to give the nitrone.

Taking the second step in the proposed mechanism as the rate determining step, the rate of disappearance of $\mathrm{K}_{3} \mathrm{Fe}(\mathrm{CN})_{6}$ is given by equation 9 . :

$$
\left.\frac{-\mathrm{d}\left[\mathrm{K}_{3}\right.}{\mathrm{dt}} \mathrm{Fe}(\mathrm{CN})_{6}\right]=\mathrm{k}_{2}[\mathrm{HCF}(\mathrm{III})][\text { Py-anion }]
$$




$$
\begin{aligned}
& \text { Py-anion }=\text { pyrollidinium anion } \\
& \text { from step I in the scheme } \\
& \mathrm{K}=\frac{[\mathrm{Py} \text {-anion }]}{[\mathrm{Py}]\left[\mathrm{OH}^{-}\right]}
\end{aligned}
$$

Therefore $\quad-\underline{d}\left[\mathrm{~K}_{3} \mathrm{Fe}(\mathrm{CN})_{{ }_{i j}}\right]=\mathrm{k}_{2}[\mathrm{HCF}(\mathrm{III})][$ Py-anion $]$ $d t$

$$
=\mathrm{k}_{2} \mathrm{~K}[\mathrm{HCF}(\mathrm{III})][\mathrm{Py}]\left[\mathrm{OH}^{-}\right]
$$

$$
\begin{aligned}
& \text { Since } \quad \mathrm{K}_{\mathrm{v}}=\left[\mathrm{H}^{+}\right]\left[\mathrm{OH}^{-}\right] \\
& -\mathrm{d}\left[\mathrm{K}_{3} \mathrm{Fe}(\mathrm{CN})_{6}\right]=\mathrm{k}[\mathrm{HCF}(\mathrm{III})][\mathrm{Py}]\left[\mathrm{H}^{+}\right]^{-1} \\
& \mathrm{dt}
\end{aligned}
$$

Hence scheme I provides satisfactory explanation for the experimental results.

Finally it can be concluded that this reaction demonstrates the usefulness of hexacyanoferrate(III) as a reagent which can convert cyclic aliphatic secondary amines to nitrones (piperidine also gives the corresponding nitrone, unpublished data, SLAAS, 1992) which are important intermediates to synthesize a wide variety of organic compounds. This is in contrast to the reaction of hexacyanoferrate(III) with aromatic secondary amines where oxidation of $\mathrm{N}$-alkyl side chain takes place (unpublished results, SLAAS, 1995).

\section{Acknowledgement}

The authors wish to thank Prof. A.S. Amarasekara, University of Colombo for helpful suggestions.

\section{References}

1. Audeh C.A. \& Smith J.R.L. (1970). Amine oxidation - II Oxidation of some trialkyl amines with alkaline potassium hexacyanoferrate (III), Journal of Chemical Society (B) : 1280

2. Rao V.S., Sethuran B. \& Rao T.N. (1979). Mechanism of oxidation of esters by $\mathrm{Ce}^{4+}$ in the absence and presence of $\mathrm{Ag}(\mathrm{I})$ : a kinetic study. Indian Journal of Chemistry $17: 260$

3. Ball S. \& Bruice T. (1980). Oxidation of amines by a 4 a - hydroperoxyflavin. Journal of the American Chemical Society 102: 6498. 
4. Deraniyagala S.P. \& Premasiri T.N.T. (1999). Kinetics and mechanism of oxidation of ethylacetate by potassium permanganate in acidic medium. Vidyodaya Journal of Science $\mathbf{8}$, in press

5. Takano S. \& Schishido K. (1981). General synthetic approach to the quinalizidine alkaloids via a $(2+3)$ - cyclo addilion. Journal of the Chemical Society Chemical Communications. 940.

6. DeShong P. \& Leginus J.M. (1983). Stereospecific synthesis of racemic daunosamine diasterofacial selectivity in a nitrone cycloaddition. Journal of the American Chemical Society $105: 1686$

7. Jeffery G.H., Basset J., Mendham J. \& Denney R.C. (1989). Vogels text book of quantitative chemical analysis pp 399 ELBS (Longman)

8. Murahashi S. \& Shiota T. (1987). Selenium dioxide catalyzed oxidation of secondary amine with hydrogen peroxide. Simple synthesis of nitrones from secondary amines. Tetrahedron Letters $28: 2383-2386$ 